\title{
Parent Training Intervention for Parents from Different Cultural Backgrounds with Children with Behavioral Problems
}

\author{
Francesca Cuzzocrea, Oliva Patrizia, Larcan Rosalba, Murdaca Anna Maria \\ Department of Human and Social Sciences, University of Messina, Messina, Italy \\ Email: fcuzzocrea@unime.it
}

Received November $28^{\text {th }}, 2012$; revised December $24^{\text {th }}, 2012$; accepted January $21^{\text {st }}, 2013$

\begin{abstract}
The main objective of this paper is to carry out a parent training with parents from different cultural background with a dual purpose: a) providing basic educational skills that disregard the cultural differences and b) verify the effectiveness of training and maintenance of skills learned. This research was designed both to verify whether a program of parent-training group can modify the parent-child interactions in different cultural contexts than the Italian, and to provide a service to families who, for different reasons, can be considered "at risk". The work was carried out separately on Italian and Sri Lankan groups of parents of non-compliant children. Both groups learned, by attending training sessions, educational techniques proposed and put them into practice with their children in different interactive contexts.
\end{abstract}

Keywords: Parent Training; Intercultural Approach; Family; Compliance; Behavior Modification

\section{Introduction}

Every family is a system that lives in a particular time and moves in a given space (Sponchiado, 2001). Kagitçibasi (1990) proposes an evolutional model of the family which shows the mutual influences between the context and the family system, and explains the evolution of the family in relation to socioeconomic development, creating causal analysis/functional development of the self.

The family brings values and processes of socialization that enable us to understand the variability between the size of independence and interdependence values. The individual acquires values within the family that determine the opening (tendency to socialization - community) or close relations to the outside (isolationism-individualism). Even family's interactions, designed as educational styles, influence the development of the child's personality and, consequently, social development and relationships. The children spend most of their time in the household, and in some cases, it is necessary to modify the parental relationships so that the child learns to emit behaviors within the family and to generalize them in the social context.

Not all families have the specific skills needed to solve the problems present in their educational management. This means that the probability of failure increases causing adverse effects in individual components and within the entire family system. For this reason, in the $60 \mathrm{~s}$ was made an increasing number of researches using parent-training to analyze and solve a wide variety of problems relating to the parent-child relationship. The interest in this type of surgery comes mainly from the possibility of combining the need for a scientific study with the opportunity to provide a service that uses the methods whose validity has been adequately tested (Larcan, 1998; Larcan, Cuzzocrea, \& Trifirò, 1999; Lundahl, Risser, \& Lovejoy, 2006). Perhaps for this reason, several studies are geared towards behavioral parent training guidance. The choice of this type of intervention is amply justified, in fact, by an extensive national and international literature that documents the effectiveness in different contexts and in relation to different family problems (Danforth, Harvey, \& Ulaszek, 2006; Crockett, Fleming, Doepke, \& Stevens, 2007).

Among many preventive interventions proposed by applied research in recent decades, the education of parents, and in particular the behavioral parent training matrix, allows to improve the quality of parent training, breaking the cycles of coercion in which many families seem hopelessly trapped, resizing conducted noncompliant children, which could, if not properly managed, evolve into antisocial behavior (Patterson, De Baryshe, \& Ramsey, 1989; Serketich \& Dumas, 1996; Schrepferman \& Snyder, 2002; Piquero, Farrington, Welsh, Tremblay, \& Jennings, 2009).

The applied research proposed here is, therefore, within the systemic-behavioral model of development and falls within the broad overview of the programs of parent-education, or training of parents and support budget. These programs are different in many respects from the traditional procedures (Larcan, Oliva, $\&$ Sorrenti, 2008), and they are intended primarily to convey to parents a based educational culture. They do not transfer simply therapeutic techniques aimed at circumscribed problems. This is accomplished by helping parents to plan, in the context of natural interaction with their child, a number of development opportunities, to reduce or prevent severe forms of behavioral problems (deviance, delinquency, etc.). These problems, if not properly dealt with, are accentuated over time, burdening the family even further. In addition, within the family intends to remove the factors that maintain problem behaviors and dysfunctional. Unlike similar initiatives, this program is characterized by methodological rigor and scientific background supporting it, referring to specific learning techniques, previously tested and validated. Parents are led gradually to acquire the necessary skills to family management and education with the aim not to "approve" the parents, but to gain awareness of the dynamics underlying the educational relationship, and thus enable them to manage independently and according to its principles and objectives, the education and training of children. 


\section{Training Aims}

This research was carried out on two different sets of parents, a group was formed by Italian parents (actually Sicilian) and a group was formed by Sri Lankan parents (living in Sicily). The preliminary goal was to analyze the two educational models and therefore to realize a search in the direction suggested by Kagitçibasi (1996). The cross-cultural approach (Kagitçibasi, 1996), in particular, analyze and evaluate the effectiveness of training, comparing, in full respect of each other's cultural identity in the context of family management, families from different cultural backgrounds by identifying points of contact and differences that may provide useful information from the perspective of an educational intervention in real-cultural integration. In addition, it was intended to determine whether a parent training behavior, with the necessary cultural adjustments, could be equally effective to resolve (and prevent) the behavioral and relational problems of families with different cultural backgrounds (specifically, Sicilian and Sinhalese). In line with the theoretical and methodological characteristics and structure of parent education, the main objective was to teach parents the most basic behavioral management skills in order to make them more aware of their role as agents of change and to help them out of the cycle of coercion, teaching them the basic techniques of parenting, that is, suggesting to them a few simple educational strategies, which could increase the efficiency of their operations and improve their relationship with their children. It is expected, then, that parents who would have seen that by changing their behavior, obtained significant change in children's behavior.

\section{Method}

\section{Participants}

Given the specificity of the situation, it was possible to carry out random sampling, but were allowed to join the program all parents who, after an initial meeting, during which they were explained the purpose of the project and the amount of "effort required", have agreed to take part. The work was carried out separately on the two groups of parents.

In particular, the Sicilian parents of non-compliant children were contacted on the recommendation of a secondary school, located in the province of Messina. 10 families and, among these, only seven have completed all stages of the research and were admitted to the program. The sample of Italian parents is therefore made up of 7 pairs of parents aged between 35 and 47 years $(\mathrm{M}=39.25, \mathrm{SD}=4.06)$, all from low socio-cultural level (analyzing their school level and economic situation). The latter was measured by reference to standard parameters, including mainly the profession and qualification.

Each parent must fill out a form in which they were requests information about the personal data (age, occupation, family composition) and also had to report problems in your family ménage, referring in particular to the behavior of children considered inadequate. In most cases, behavioral disorders were related not only to the children who attended the school from which they were reported, but also the other children, revealing almost always problems in the parent-child relationship and monitoring difficulties. Therefore, the number of children who have been indirectly observed and treatment was 11 children, aged between 7 and 11 years $(\mathrm{M}=8.36, \mathrm{SD}=1.50)$.

The Sri Lankan group of parents of non-compliant children was formed on the recommendation and in collaboration with Caritas. To ensure the validity and effectiveness of the course, it is preferred to select the parents of the same nationality and it was decided to select Sinhalese parents (the most numerous in the area of Messina), who claimed to have difficulty in raising their children, supposed to be particularly restless and uncooperative. In spite of difficulties, some of them overcame their initial wariness and became members of the program. It was a first structured questionnaire administered in the first phase in the form of semi-structured interview, which provided information on their age and occupation, family composition and the age and description of behavioral problems of children. We didn't have the assistance of a linguistic mediator, so it is mainly used the Italian language; this resulted in a further selection of families, in which, especially in this first phase of experimentation, it was necessary to minimize the variables that could adversely affect the effectiveness of the training.

7 couples of Sinhalese or 7 fathers and 7 mothers, aged between 30 and 55 years, belonging to a medium-low sociocultural level have joined the course. Only two of the seven couples both the husband and the wife were in possession of a diploma, the remaining five couples had a lower level of education. The age of the children ranged from 10 to 12 years. No family had never participated in a training course for parents, and all parents were in Italy for at least three years and had children who attended primary school for at least one year.

Figure 1(a) shows the average percentage of negative behaviors indicated by Italian parents as the most frequent. $45 \%$ of them complained about their children's behavior of noncompliance (with meals - $20 \%$ too much television- $15 \%$, too much clutter in their personal items-10\%). In addition, parents reported that when they deny something, $25 \%$ of their children always respond aggressively, but it seems that rarely they got appropriate responses from their children $(10 \%)$. From this we can understand that $20 \%$ of the time, parents prefer to desist; they said they only intervene if and when necessary.

Sinhalese parents (Figure 1(b)) complained, in particular, the fact that their children asked for too expensive items, or to go out with friends. In addition, parents emphasized the fact that, when they could not satisfy the desires of their children or when they did not give them permission to do something, they responded aggressively (raising his voice, slamming doors, etc.). According to Sri Lankan parents, $50 \%$ of the time they asked their children to do something they did not obey and with considerable frequency $(30 \%)$ responded aggressively. In particular, they claimed to have difficulty managing the child especially when they had to go to school $(25 \%)$ or asked them to work at home or outside the home (15\%). As reported by the parents, it seems that only $10 \%$ of the children presented inappropriate behavior during meals. Parents have also underlined that only $10 \%$ of the requests child were met by the child without opposition.

\section{Procedure}

The research was organized in 5 stages: 1) pre-training; 2) training; 3) Post-training; 4) a first follow-up; three months after the end of the training; 5) and a second follow-up after six months post-training. During the pre and post training, as well as in the first and second follow-up, parents were given the same questionnaires. After the first collective meeting, when the project was presented, its objectives have been specified: 


\section{Child behaviors}

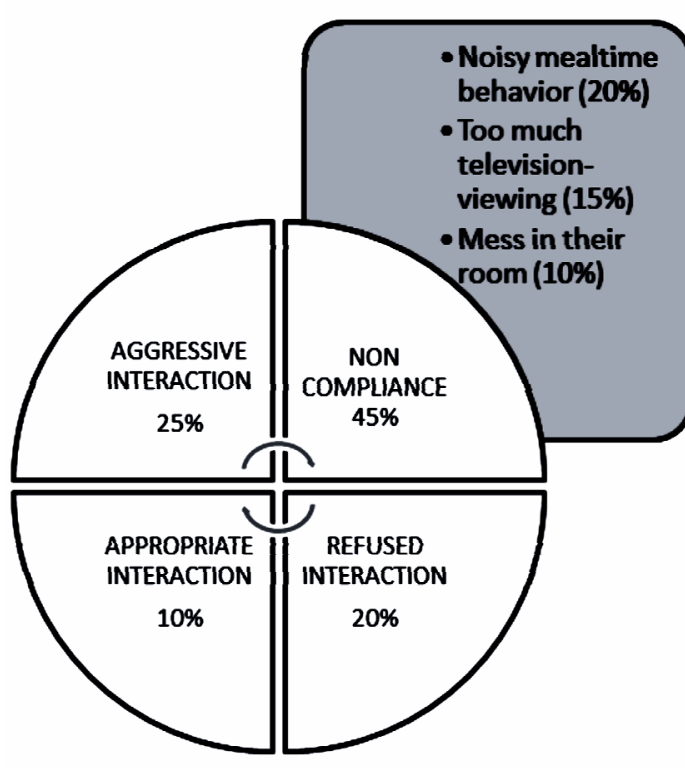

(a)

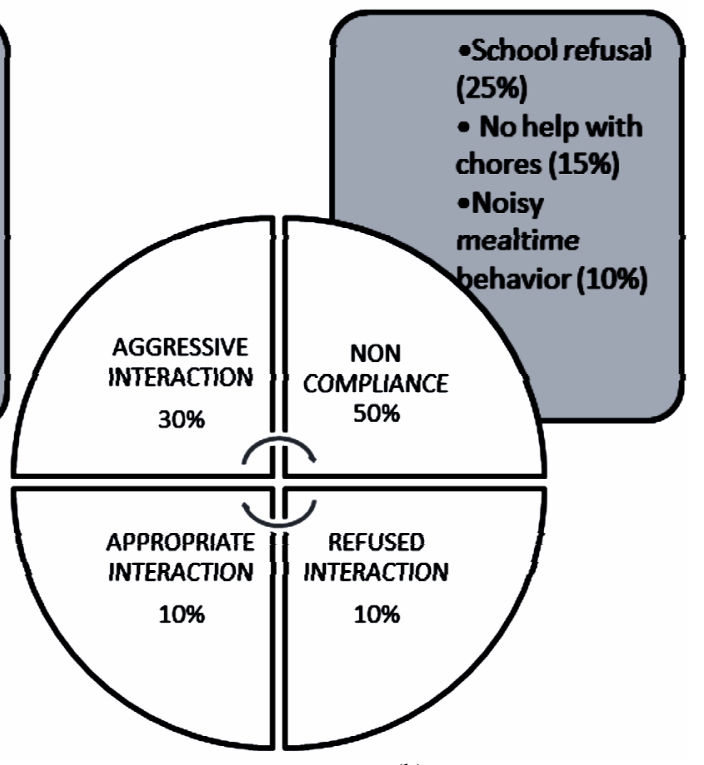

(b)

Figure 1.

Child behaviors indicated by Italian and Sinhalese parents (M\%). (a) Italian parents; (b) Sinhalese parents.

dates and general information on special needs to ensure an ongoing commitment for the duration of the course. Each family was met individually and subjected to an informal interview, which provides a more accurate knowledge of the problems, or rather, of family functioning. The training phase (phase II) was achieved mainly through group meetings, but also with individual meetings. The training (described in detail in Larcan et al., 2008), dedicated to the teaching of educational skills that are mainly based on the principles of behavior modification, provides a total of 9 meetings per week: the first three were devoted to "teaching skills, aimed at increasing appropriate behaviors". These skills are easier to learn and more immediately gratifying, while the next 4 aim to decrease inappropriate behavior. The 8 th meeting was entirely devoted to compliance. During the 9 th meeting were addressed more specific problems, related to individual cases or situations. All matches had a similar organizational structure, in order to create a more reassuring condition and a higher effectiveness. At each meeting, new skills were defined and illustrated through examples, explanations and short films, and parents were asked to practice through the process of role playing until the full achievement of a mastery level. Finally they were assigned "homework" to do at home with the guidance of a schema that contains the reminder.

\section{Measures}

To verify the effectiveness of the proposed training, in the phases of pre-training, post-training and in meetings follow-up, the following questionnaires (some of which are prepared ad hoc) were administered.

- Questionnaire A-Evaluation of the problems according to Italian parents and Sinhalese parents. Were prepared 47 items of which 13 relate to the way in which the child spends the time when at home, the 26 items on interaction behaviors acted out by his son and 8 items structured in order to assess the personal autonomy of the child $(\alpha=.79)$. Parents should mark the emission frequency of each behave- ior choosing between never, rarely, quite often, very often and always (5 Likert scale intervals). Higher scores are indicative of greater severity of the problem.

- Questionnaire B-Self-evaluation of educational behavior of the parents. Parents were asked to mark which of the behaviors listed would implement more likely in the 16 situations described in the questionnaire (behaviors usually implemented by children with similar ages to those of their children). The questionnaire consists of two types of responses: what they would do in a similar situation would (real life) and what they thought would be right to do (ideal situation). The parameters considered are the number of correct choices (behaviors appropriate education- $\alpha=.81$ ) and the number of errors (inadequate educational behaviors- $\alpha=.82$ ).

\section{Results}

The Statistical Package for Social Sciences (SPSS) was used for data analysis.

Questionnaire A-Evaluation of the problems. Table 1 shows means (M), standard deviations (SD) of data on parents' responses (Italian and Sinhalese) at different stages of assessment. The nonparametric data (relative frequency), in order to access this type of information that was provided only by sophisticated statistical tests, such as the A.NO.VA and t test, was considered essential to transform them into arcsine (Freeman \& Tukey, 1955).

For the statistical analysis, two different A.NO.VA. were separately applied to the two types of households, creating a factorial design with repeated measures 3 (different types of behavior: during the time at home vs. vs. interaction behaviors. 
personal autonomy) $\times 4$ (different phases of administration: pre-training vs. post-training; I follow-up vs. II follow-up).

Evaluation of the extent of the problems in Italian parentsThe analysis has highlighted significant differences between all the variables considered. In particular, there were highly significant differences between the 3 different types of behavior (time at home vs. interaction behaviors vs. personal autonomy) $\left(\mathrm{F}_{2,26}=9.608, p<.01\right)$ and at different stages of administration $\left(\mathrm{F}_{3,177}=32.273, p<.01\right)$. The interaction between these two factors was highly significant $\left(\mathrm{F}_{6,177}=3318, p<.01\right)$. In particular, there were highly significant differences between the 3 different types of behavior (time at home vs. interaction behaviors vs. personal autonomy) $\left(\mathrm{F}_{2,26}=9.608, p<.01\right)$ and at different stages of administration $\left(\mathrm{F}_{3,177}=32.273, p<.01\right)$. The interaction between these two factors was highly significant $\left(\mathrm{F}_{6,177}=3318, p<.01\right)$.

Evaluation of the extent of the problems in Sri Lankan parents-The data, processed in arcsine with the formula of Freeman and Tukey (1955), were analyzed by analysis of variance (A.NO.VA.) which has allowed, even in this family context, to highlight significant differences between all the variables taken into account. In particular, there were highly significant differences between the 3 different types of behavior (time at home vs. interaction behaviors vs. personal autonomy) $\left(\mathrm{F}_{3,63}=10.608\right.$, $p<.01)$ and at different stages of administration $\left(\mathrm{F}_{3,63}=9.44, p\right.$ $<.05)$. In particular, there were highly significant differences between the 3 different types of behavior and the phases of administration (time at home vs. interaction behaviors vs. personal autonomy) $\left(\mathrm{F}_{2,21}=3.83, p<.05\right)$.

These differences are evident by observing Figure 2, in which it is possible to temporarily experience a progressive decrease of the evaluation of the extent of the problems made by Italian parents (Figure 2(a)) during the four doses of the questionnaire, especially between the first and the second detection. In particular, in the post-training evaluation is observed (as a percentage) far less negative children's problems in all three areas considered behavioral changes and this change remains constant both in the first follow-up, carried out after three months, and in the second carried out six months after the end of training.

Table 1.

Mean (M), standard deviation (SD) scores of Questionnaire A, reported by Italian and Sinhalese parents.

\begin{tabular}{lllllllll}
\hline & \multicolumn{7}{l}{ Italian parents $(\mathrm{N}=14)$} & \multicolumn{7}{l}{ Sinhalese parents $(\mathrm{N}=14)$} \\
\hline & $\mathrm{T} 1$ & $\mathrm{~T} 2$ & $\mathrm{~T} 3$ & $\mathrm{~T} 4$ & $\mathrm{~T} 1$ & $\mathrm{~T} 2$ & $\mathrm{~T} 3$ & $\mathrm{~T} 4$ \\
& $\mathrm{M}(\mathrm{SD})$ & $\mathrm{M}(\mathrm{SD})$ & $\mathrm{M}(\mathrm{SD})$ & $\mathrm{M}(\mathrm{SD})$ & $\mathrm{M}(\mathrm{SD})$ & $\mathrm{M}(\mathrm{SD})$ & $\mathrm{M}(\mathrm{SD})$ & $\mathrm{M}(\mathrm{SD})$ \\
Time at home & $1.56(.17)$ & $1.4(.19)$ & $1.42(.21)$ & $1.34(.13)$ & $1.17(.18)$ & $1.01(.19)$ & $1.08(.13)$ & $1.12(.21)$ \\
Interaction behaviors & $1.16(.23)$ & $.97(.17)$ & $.93(.16)$ & $.91(.12)$ & $1.03(.21)$ & $.89(.18)$ & $.85(.15)$ & $.78(.22)$ \\
Personal autonomy & $1.35(.44)$ & $1.1(.44)$ & $.88(.37)$ & $.94(.28)$ & $1.07(.31)$ & $.85(.33)$ & $.73(.37)$ & $.69(.32)$ \\
\hline
\end{tabular}

Note: T1: pre-training; T2: post-training; T3: I follow-up; T4: II follow-up.

Problem behaviors' evaluation

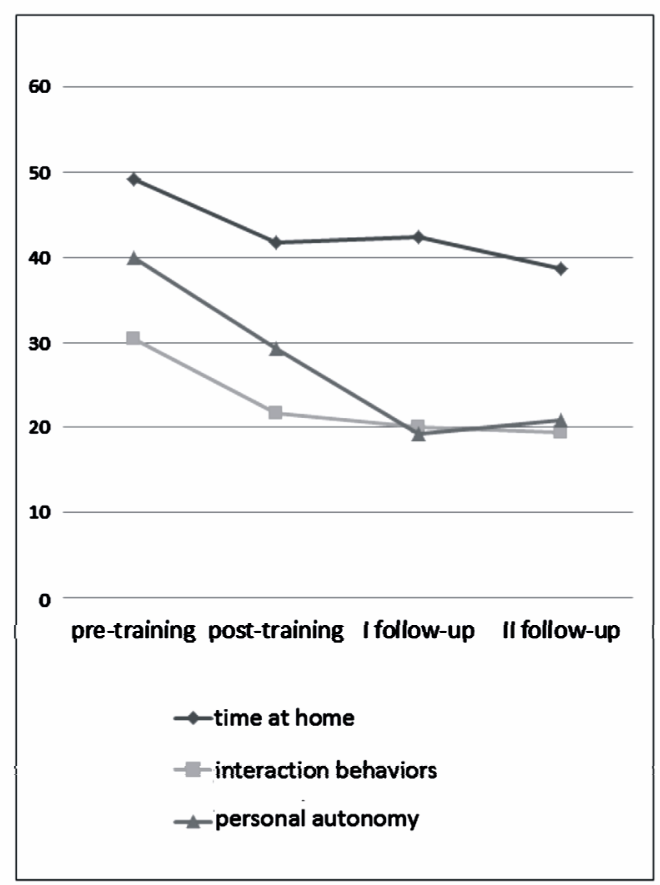

(a)

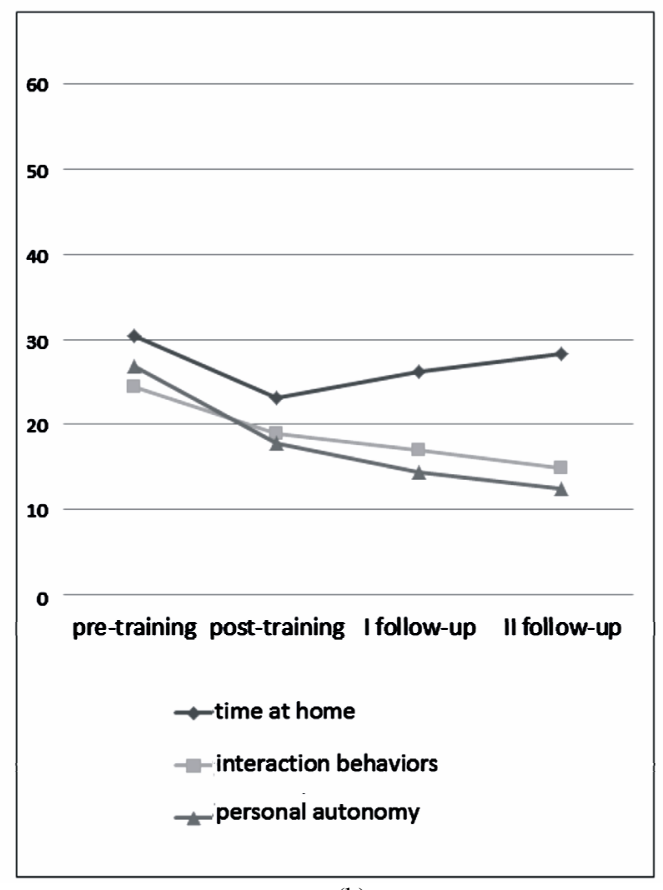

(b)

Figure 2.

Results (M\%) of questionnaire a reported by italian and sinhalese parents. (a) Italian parents; (b) Sinhalese parents. 
In measurements of follow-up, although it is evident a significant improvement in the assessment of the extent of problems compared to the baseline situation, there are significant differences between the investigated areas (time at home, interaction behaviors, personal autonomy). Three months later, in fact, the improvement registered is unchanged with regard to the behaviors of interaction and behavior at home, while there is a further improvement with regard to personal autonomy. After six months, there is a slight but significant further reducetion of the problems at home, and the maintenance of the changes occurred in the other two areas (interaction behaviors). Observing graphical representation of the evaluation carried out by Sinhalese parents (Figure 2(b)), it is possible to experience, temporarily, a progressive decrease of the evaluation of the extent of the problems made by the parents in the post-test; in fact, we observe an evaluation (in percent) far less negative in children's problems in all three areas of behavior considered. This change, however, does not remain constant during the first follow-up, carried out after three months, there has been a further increase in the assessment of the conduct at home, while it is evident a significant improvement in the assessment of the extent of problems in the personal autonomy and interactions with parents/children.

Questionnaire B-Self-evaluation of educational behavior of the parents. Table 2 show the means (M), standard deviations (SD) of the data processed in arcsine using the Freeman and Tukey's formula (1955) relating to the marks obtained by Italian parents and Sinhalese parents in the Questionnaire B.

It's important to remember that in the questionnaire B there were two types of responses: what parents would have done in a similar situation (real life) and what they thought would be right to do (ideal situation), and that the parameters considered were the number of the correct choices and the number of errors (wrong choices). Therefore, the statistical analysis consisted in the application of test AN.O.VA with a factorial design repeated measures 2 (actual behavior vs. ideal behavior) $\times$ 2 (correct vs. incorrect choices) $\times 4$ (questionnaire phases), examining separately two different groups. Self-evaluation of Italian parents' educational behavior-The analysis of the results has revealed significant differences in the actually implemented behavior by Italian parents and those considered more correct, at least in theory, in response to the behavior of children $\left(F_{1,24}=7.25, p<.01\right)$. Were also highlighted highly significant differences between the right answers and the wrong ones $\left(\mathrm{F}_{1,24}=617,806, p<.01\right)$, and between the different phases of detection $\left(\mathrm{F}_{3,144}=3267, p<.05\right)$. In addition, the effect which exist in the interaction between the type of responses (right/wrong) in the different phases of detection $\left(\mathrm{F}_{3,144}\right.$ $=137.03, p<.01)$ seems to be relevant. Self-assessment of Sri Lankan parents' educational conduct-Similar results were obtained in the sample of Sinhalese parents. Indeed, analysis of variance (AN.O.VA) of the factorial design repeated measures 2 (actual behavior vs. ideal behavior) $\times 2$ (correct vs. incorrect choices) $\times 4$ (phases of the questionnaire) found significant differences between the right answers and the wrong ones $\left(F_{1,14}\right.$ $=584.832, p<.01$ ), and between the different phases of detection $\left(\mathrm{F}_{3,96}=348.111, p<.01\right)$. In addition, the effect which exist in the interaction between the type of responses (right/ wrong $)$ in the different phases of detection $\left(\mathrm{F}_{3,96}=348.222\right.$; $p$ $<.01)$ seems to be relevant. In Figure 3, where are represented the average percentage of the raw scores obtained in the questionnaire B by Italian parents (correct answers: Figure 3(a) wrong answers: Figure 3(b)), you can "see" better the effects of training. In fact, in the post-test it is clear that parents have improved their ability to evaluate what would be better for them to do in different situations, and how they have learned to implement the principles acquired. At the same time, there was a significant reduction in bad behavior. In first follow-up parents seem to show greater, although not significant, difficulties in implementing the techniques they had previously learned; although they maintain the ability to correctly assess what they should do. It also noted an increase (not significant) in the number of wrong answers. In the 2nd follow-up parenting skills seem to stabilize, both in reference to the correct answers, and to still make mistakes.

As it is showed in Figures 4(a) (right answers) and 4(b) (wrong answers), even the Sri Lankan parents seem to have gained more educational skills. In fact, in the post-test it is clear that parents have improved their ability to evaluate what would be better for them to do in different situations, and how they have learned to implement the principles acquired. At the same time, there was a significant reduction in bad behavior.

In fact, even if the claims made by the parents in the questionnaire reveal a sufficient amount of appropriate educational behaviors, in pre-training phase incorrect answers are too frequent. Furthermore, it appears that parents are quite convinced of the correctness of their educational methods, it is clear that the assessment of what is right to do and the conviction of what they would do in different situations coincide almost perfectly. In first follow-up parents seem to show a greater, although not statistically significant, parenting skills (increase of correct answers), while there is a significant reduction of incorrect

Table 2.

Mean (M), standard deviation (SD) scores of questionnaire B, reported by Italian and sinhalese parents.

\begin{tabular}{|c|c|c|c|c|c|c|c|c|c|}
\hline & & \multicolumn{4}{|c|}{ Italian parents $(\mathrm{N}=14)$} & \multicolumn{4}{|c|}{ Sinhalese parents $(N=14)$} \\
\hline & & Т 1 & Т 2 & T 3 & $\mathrm{~T} 4$ & T 1 & Т 2 & Т 3 & $\mathrm{~T} 4$ \\
\hline & & $\mathrm{M}(\mathrm{SD})$ & $\mathrm{M}(\mathrm{SD})$ & $\mathrm{M}(\mathrm{SD})$ & $\mathrm{M}(\mathrm{SD})$ & $\mathrm{M}(\mathrm{SD})$ & $\mathrm{M}(\mathrm{SD})$ & $\mathrm{M}(\mathrm{SD})$ & $\mathrm{M}(\mathrm{SD})$ \\
\hline \multirow{2}{*}{ Real situation } & Correct choice & $1.38(.37)$ & $2.03(.24)$ & $2.18(.17)$ & $2.21(.15)$ & $1.88(.17)$ & $2.03(.19)$ & $2.27(.27)$ & $2.12(.22)$ \\
\hline & Incorrect choice & $.94(.21)$ & $.68(.25)$ & $.43(.2)$ & $.31(.18)$ & $.89(.18)$ & $.69(.18)$ & $.42(.26)$ & $.58(.20)$ \\
\hline \multirow{2}{*}{ Ideal situation } & Correct choice & $1.78(.19)$ & $2.07(.23)$ & $2.18(.17)$ & $2.21(.15)$ & $1.88(.17)$ & $2.03(.19)$ & $2.28(.27)$ & $2.14(.22)$ \\
\hline & Incorrect choice & $.94(.22)$ & $.62(.29)$ & $.43(.2)$ & $.311(.18)$ & $.88(.17)$ & $.69(.18)$ & $.42(.26)$ & $.58(.2)$ \\
\hline
\end{tabular}

Note: T1: pre-training; T2: post-training; T3: I follow-up; T4: II follow-up. 
F. CUZZOCREA ET AL.

Italian parents' choice

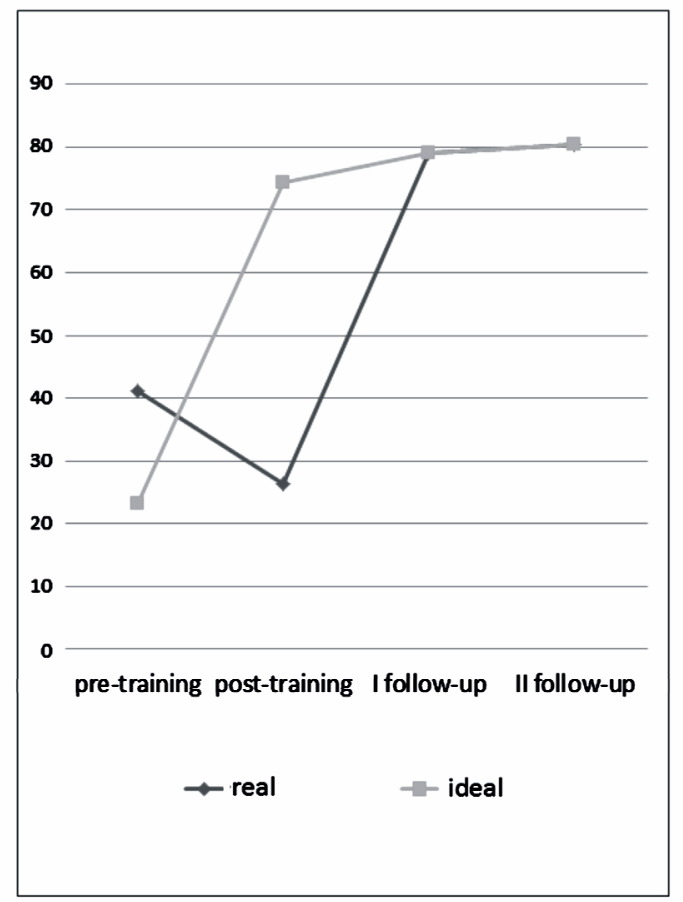

(a)

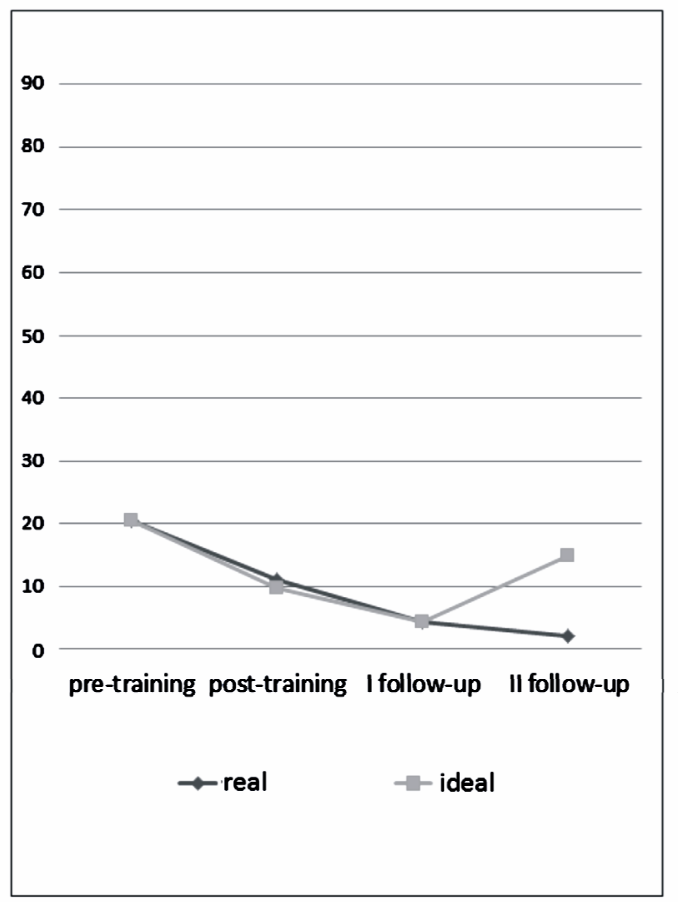

(b)

Figure 3.

Results (M\%) of questionnaire B reported by italian parents. (a) Correct choice; (b) Incorrect choice.

\section{Sinhalese parents' choice}

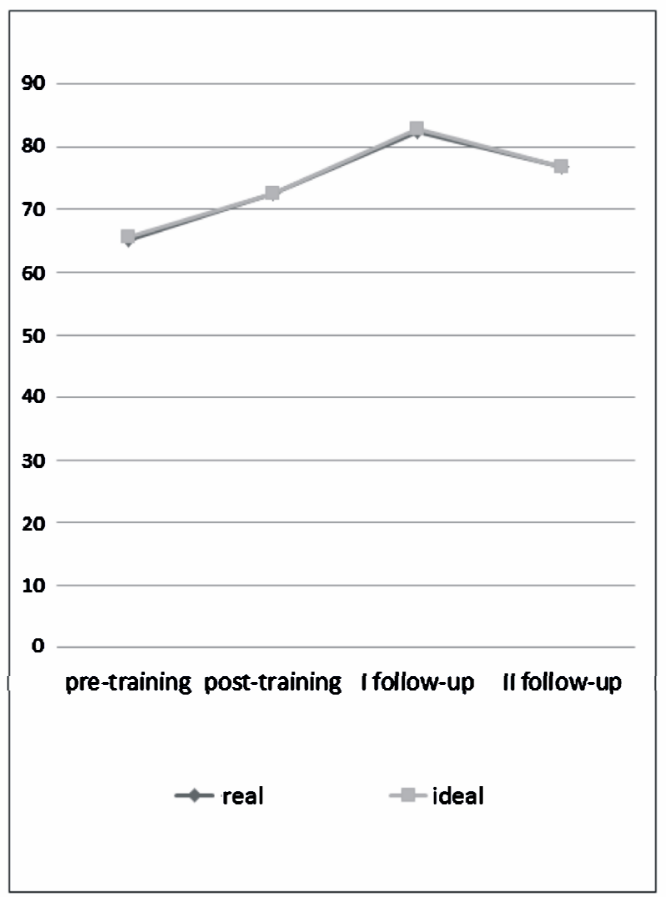

(a)

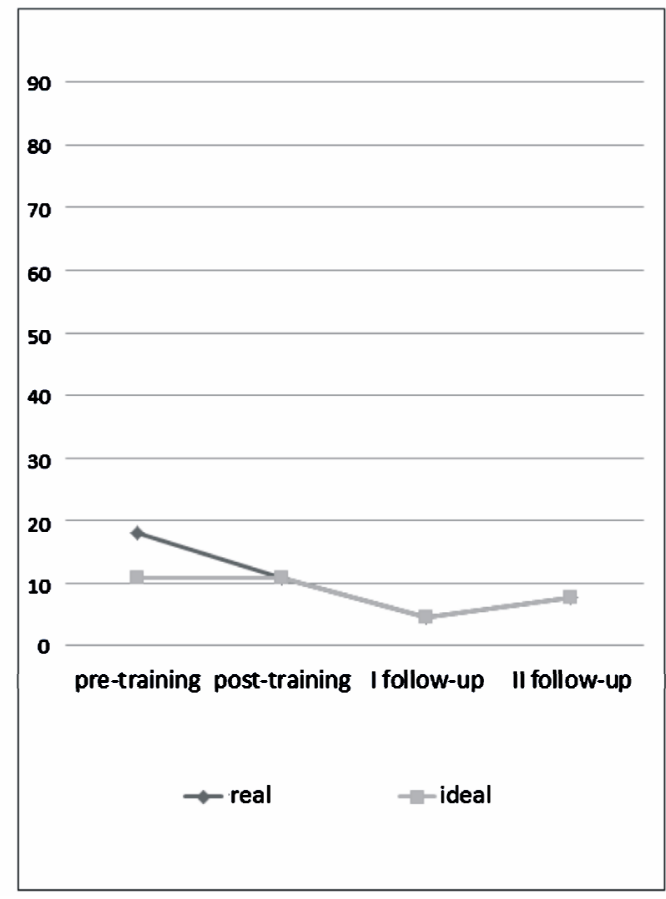

(b)

Figure 4.

Results (M\%) of questionnaire B reported by sinhalese parents. (a) Correct choice; (b) Incorrect choice. 
answers. Parents seem to have understood their "mistakes" and claim to implement different educational methods. In the 2nd follow-up, however, it is observed that the correct answers are reduced (although not significantly), while there is a significant increase in incorrect answers.

\section{Discussion}

The main objective of this research was to evaluate the efficacy of a treatment for parents, foreign and local, in children with mild non-compliance conduct. The intervention was aimed primarily at encouraging, in familiar contexts, educational management skills of parents and reduces, therefore, the behavior of children's non-compliance.

To verify the effectiveness of the training, it was considered useful to refer to the average scores obtained by the "group" of parents in each of the instruments used in the various stages of assessment. This is to verify that for the parameters considered (perception and evaluation of the extent of the problems from parents, knowledge of the principles of educational psychology and management skills education), compared to the baseline situation (baseline), there were significant changes as a result of training and whether they were maintained over time.

Assessments carried out by Italian parents-The areas that are assessed as most problematic were those of personal autonomy. The maladaptive behaviors were obviously higher frequent than those evaluated with the highest levels of undesirability. The training seems to have proved effectiveness in this direction because the evaluation of the frequency of maladaptive behaviors (referred to as undesirable) was significantly reduced and it was found also a good maintenance of the change, even nine months after the end of the training. Further confirmation of the effectiveness of the training is the evaluation of the skills of parenting: in fact the proportion of correct answers increased significantly, and at the same time, has reduced the number of errors, the parents of both groups have gained a greater awareness of how it would be better to behave in certain situations of educational criticism. The fact that in the follow-up distance there has been a gradual ascent of unfair educational practices suggests the need of further more frequent reminders of the skills learned during the training and testing more straightforward (in vivo) of the interactions parents/children.

Assessments carried out by Sri Lankan parents-In this case, the statistical analysis of the results allowed us to verify the effectiveness of the training course for parents, and because it was possible to scale the evaluation of the extent of the problems made by the parents, but especially because it seems to have provided them with appropriate educational tools. In fact, Sinhalese parents showed already in the pre-training adequate parenting skills, although they still use too often inadequate educational strategies. The training had the function on the one hand to reduce the "errors" and on the other hand education makes parents able to choose the most appropriate educational methods in response to each specific problem. It was found, however, insufficient process of generalization and maintenance of skills learned in response to each specific problem. In fact, six months after the conclusion of the course there is a change in trend: parents tended to commit new errors even though they are not serious. In the second follow-up the same parents say they still have, albeit to a lesser extent than before, some problems of interaction with the child, but that has defi- nitely improved his behavior (aggressive responses were reduced and increased capabilities of personal autonomy). It is, therefore, once again confirmed the hypothesis that the acquisition of effective skills management education fosters interactions parent/child acting positively on the sense of parental self-efficacy.

It is important to underline that the results are obviously not generalizable, due to some methodological limitations, including the small numbers of parents and not entirely rigorous selection procedures, but may represent a further confirmation of the effectiveness of parent training use.

\section{Conclusion}

Both groups learned, by attending training sessions, educational techniques proposed and put them into practice with their children in different interactive contexts. The educational skills acquired immediately after the training make parents sufficiently maintained over time (follow-up), although the correctness of educational performance has suffered some decline (while maintaining awareness of the mistakes). The children's behavior has improved in parallel and consistently, especially in the areas of greatest interest (conducted interactive and personal autonomy), and the change recorded in the post-training has remained constant or even increased, with the passage of time. The reduction of inappropriate behaviors of children (real or perceived as negative by parents), the increase in educational skills of the parents, the probable reduction of their educational inconsistencies, co-presence to the training of fathers and mothers, have undoubtedly influenced processes of family interaction, creating a functional and a favorable educational environment. Analyzing the results achieved by each family, we can, however, draw some guidelines for the implementation of possible future research. A first consideration is the participation of fathers in training. The presence of both members of the couple in parental training and the resulting total parental complicity in renewing the educational project, has certainly enhanced the effects of training. In fact, the most significant predictor of educational success is always the motivational drive that leads the first single parent to take this experiential path and then to develop a new educational system investing all his/her resources. In spite of the fact that some of the problems related to conduct disorders that parents have to face are less serious than others, parents can benefit from a specific course anyway (Larcan, 1996; 1998; Lundahl et al., 2006; Larcan et al., 2008). Another important consideration concerns a fundamental component of any successful intervention training: the generalization processes activated during and after the learning period. In addition in order to teach proper and effective educational strategies, which become part of the behavioral repertoire of each parent firm, the training should, in fact, enhance their ability to use the skills acquired in a variety of different educational contexts and situations. It should, therefore, emphasize the need to organize longer training sessions, periodic follow-up calls and, the most frequent, the encouragement of selfregulation skills through parents who, during the training, were predominantly hetero- regulated by the trainer. Today, the program of parent training itself is an experimental model of a greater and decisive intervention project aimed at preventing relational disorders in the family. This project provides the possibility of early detection, with appropriate assessment tools, various conditions of risk, and therefore, to intervene very early, 
before the discomfort occurs. The parent training would not be a simple intervention technique, but it could become an effective prevention tool, especially if it was made permanent as parental support, particularly in the areas and familiar contexts at risk (Barker, Cook, \& Borrego, 2010).

\section{REFERENCES}

Barker, C. H., Cook, K. L, \& Borrego, J. (2010). Addressing cultural variables in parent training programs with latino families. Cognitive and Behavioral Practice, 17, 157-166. doi:10.1016/j.cbpra.2010.01.002

Bronfenbrenner, U. (1979). The ecology of human development. Experiments by nature and design. Cambridge: Harvard University Press.

Crockett, J., Fleming, R. K., Doepke, K. J., \& Stevens, J. (2007). Parent training: Acquisition and generalization of discrete trials teaching skills with parents of children with autism. Research in Developmental Disabilities, 28, 23-36. doi:10.1016/j.ridd.2005.10.003

Cuzzocrea, F., \& Larcan, R., (2005). Parent training for families with mentally retarded children. Journal of Applied Radical Behavior Analysis (JARBA), 1, 21-31.

Danforth, J. S., Harvey, E., Ulaszek, W. R., \& McKee, T. E. (2006). The outcome of group parent training for families of children with attention-deficit hyperactivity disorder and defiant/aggressive behavior. Journal of Behavior Therapy and Experimental Psychiatry, 37, 188-205. doi:10.1016/j.jbtep.2005.05.009

Freeman, M. F., \& Tukey, J. W. (1955). Transformation related to angular and square root. Annuals of Mathematics and Statistics, 21, 607. doi:10.1214/aoms/1177729756

Kagitçibasi, Ç. (1990). Family and socialization in cross-cultural perspective: A model of change. In J. Berman (Ed.), Cross-cultural perspective: Nebraska symposium an motivation (pp. 135-200). Lincon, NE: Nebraska University Press.

Kagitçibasi, Ç. (1996). Family and human development across cultural. New Jersey: Lawrence Erlbaum Associates Publishers.

Larcan, R. (1996). Analisi del comportamento deviante secondo una prospettiva evolutivo-comportamentale. In A. Mangano, \& A. Michelin-Salomon (Eds), La devianza dei minori come problema educativo. Roma: P. Lacaita Ed.

Larcan, R., (1998). Un progetto di intervento per la prevenzione di problemi comportamentali in età evolutiva. In R. Larcan, \& M. A. D. Vita (Eds), Crescere nella complessità: La prevenzione del rischio nella dimensione educativa e relazionale. Milano: Unicopli.

Larcan, R., Cuzzocrea, F., \& Trifirò, I. (1999). Parent training di gruppo per la prevenzione di comportamenti antisociali. Pre-atti, $X$ Congresso Nazionale AIAMC, Napoli, 26-28 Novembre 1999, 44-45.

Larcan, R., \& Cuzzocrea, F., (2002). Parent training for families with mental retarded children. Pre-atti, Fourth European Conference Psychological Theory and Research on Mental Retardation and Cognitive Developmental Disabilities (MRCD), Catania, 23-25 May 2002, 40.

Larcan, R., Oliva, P., \& Sorrenti, L. (2008). Interventi psicologici sulla famiglia. Padova: Piccin.

Lundahl, B., Risser, H. J., \& Lovejoy, M. C. (2006). A meta-analysis of parent training: Moderators and follow-up effects. Clinical Psychology Review, 26, 86-104 doi:10.1016/j.cpr.2005.07.004

Patterson, G. R., De Baryshe, B. D., \& Ramsey, E. (1989). A developmental perspective on antisocial behavior. American Psychologist, 44, 329-335. doi:10.1037/0003-066X.44.2.329

Piquero, A. R., Farrington, D. P, Welsh, B. C., Tremblay, L. R., \& Jennings, W. G. (2009). Effects of early family/parent training programs on antisocial behavior \& delinquency. Journal of Experimental Criminology, 5, 83-120. doi:10.1007/s11292-009-9072-x

Schrepferman, L., \& Snyder, J. (2002). Coercion: The link between treatment mechanisms in behavioral parent training and risk reduction in child antisocial behavior. Behavior Therapy, 33, 339-359. doi:10.1016/S0005-7894

Serketich, W. J., \& Dumas, J. E. (1996). The effectiveness of behavioral parent training to modify antisocial behavior in children: A meta-analysis. Behavior Therapy, 27, 171-186. doi:10.1016/S0005-7894(96)80013-X

Sponchiado, E. (2001). Capire le famiglie. Le Bussole: Carocci. 